\title{
The evolutionary and disruptive potential of Industrie 4.0
}

\author{
JOHANNES WINTER ${ }^{1}$
}

\begin{abstract}
Despite all the hype, digitalization is not a new trend. The third industrial revolution started as early as the beginning of the 1970s and has continued to this day. It is shaped using electronics and information technologies (IT) in the economy and progressive standardization and automation of business processes. While exponential growth is typical for the IT sector, this is rarely the case for the classic industries. For a long time, the change was barely perceivable, which led many players to denounce these developments as uninteresting, losing interest at an early stage. But then, as the process picks up breakneck speeds, it often becomes impossible to jump on board or keep up. When automation driven by electronics and IT established itself in production, it led to dramatic changes in value chains and employment structures. Through standardization and automation, business processes became more efficient, quicker, and transparent. When the dot-com speculative bubble burst in 2000, vending machines that ordered supplies independently were already in operation. In the search for the business model of the Information Age, electronic marketplaces became popular pioneers for dynamic business networks and real-time business. Many of today's well-known technology firms - such as Google, Netflix, or the predecessors of Facebook - were already active on the market in a similar form. In recent years a second wave of digital transformation is experienced and with it, a fourth industrial revolution. The necessary information and communication technologies have now become so cost-effective that they can be used in widespread areas. As a result, many of the dot-com promises have been realized today. The aim of this paper is to intensify the Industrie 4.0 debate in economic geography by showing the evolutionary and disruptive potential of Industrie 4.0.
\end{abstract}

Keywords: Industrie 4.0, fourth industrial revolution, digitalization, Internet of Things, economic geography, Europe.

Received December 2019, Accepted April 2020.

\section{Introduction: the second wave of digitalization}

When it comes to the second wave of digitalization, mobile connected devices such as smartphones are a vital part. But first: Why do we call it the second wave, what makes the difference between the wave of digitalization today and digitalization in the early years of this millennium when the dot.com-bubble burst?

The ideas and concepts that are depicted here aren't that new, especially the concept of "everything as a service" and the even greater personalization of services and products. One aspect of this servitization and personalization is the idea that instead of buying off-the-shelf products and services we use web- and cloud-based services and we go online to buy bundles of products and services - and these bundles are individually tailored to the needs and preferences of their users. These are so-called smart services. One example of how these ideas are implemented today is "mobility as a service": In order to get from $\mathrm{A}$ to $\mathrm{B}$, people may use an app on the smartphone combining different means of transport, like car-sharing or public transportation or they choose if they would like to take the quickest or the cheapest connection.

So, what is different today? In short: the technologies that are needed to implement the ideas like "everything as a service" can now be deployed on a large scale at very low costs (DAugherty, P. and Wilson, H.J.

\footnotetext{
${ }^{1}$ National Academy of Science and Engineering (acatech), Karolinenplatz 4, 80333 Munich, Germany.

E-mail: winter@acatech.de
} 
2018). Nearly all objects, like cars and trains, machines on a factory shopfloor or household appliances can be connected to the Internet and can be equipped with sensors in order to generate, collect and exchange data. Their sensors provide us with a huge amount of real-world data at nearly no costs. This data in turn can be used to gain valuable information using data analytics and machine learning. And it can be used to develop and train autonomous systems - which will become more and more common in the course of next years.

The term "autonomous systems" can be applied not only to robots in the conventional sense but also to manufacturing systems, vehicles, buildings and software systems: for example, a system for the energy management in the smart home that adapts to the user's individual patterns of energy consumption. A system can be described as autonomous if it is capable of independently achieving a predefined goal in accordance with the demands of the current situation without recourse either to human control or detailed programming. Of course, Artificial Intelligence (AI) and machine learning (ML) play a great role in developing such systems (Acatech, 2017). This second wave of digitalization has far-reaching consequences for the economy and established business models.

So far, there has been little existing systematic research in economic geography on the topic of Industrie 4.0, which is surprising, since it can be assumed that the digital transformation of the economy could also have a regional impact. Current Industrie 4.0 research in economic geography refers to regional disparities and transformative industrial policy (BAILEY, D. and De Propris, L. 2019), national and regional comparative advantages in key enabling technologies (Ciffolilli, A. and Muscio, A. 2018), the impact on existing clusters (Göтz, M. and JANKowsKA, B. 2017), Industry 4.0 in factory economies (Szalavetz, A. 2017), socio-economic effects of smart manufacturing (Fuchs, M. 2020), and location decision and upgrading in automotive industry (HAIDER, M. 2020; Molnár, E. et al. 2020) as well as the potential of EU regions to contribute to Industry 4.0 (BAlland, P.A. et al. 2019). So far, there is a lack of a common and uniform understanding in economic geography of what Industrie 4.0 is and what spatial impact the fourth industrial revolution can have. The main purpose of this paper is to develop a common understanding of the importance and impact of Industrie 4.0 at different geographical levels, based on the conceptual and empirical considerations of the National Academy of Science and Engineering (Acatech, 2013), which introduced the term Industry 4.0 in 2013.

This contribution is empirically based, relying on primary data collected through 160 qualitative guided interviews with executives and experts from China, Germany, Japan, Korea, United Kingdom and the US conducted between September 2015 and December 2018. The in-depth interviews were transcribed and analysed using 'Qualitative Content Analysis' (Glaeser, E. and Laudel, G. 2004). (The study forms part of a research project carried out at "acatech" funded by the German Ministry of Economic Affairs and Energy.)

The study consists of six major parts. The second part demonstrates the evolutionary path of the fourth industrial revolution. The third part tries to reply to what Europe has to do in order to join to the fourth industrial revolution, while the fourth part describes the major features of a data driven economy. In the future the research fields of economic geography research will also transform, and this is introduced in the fifth part. Finally, some conclusions and outlook follow.

\section{The fourth industrial revolution - an evolutionary path}

Like in many other regions of Europe, in Western Europe industrialization began with the introduction of mechanical manufacturing in the early $19^{\text {th }}$ century, when machines such as the mechanical loom revolutionized the way goods were made. The first industrial revolution was followed by a second one at the turn of the $20^{\text {th }}$ century, which involved electrically-powered mass production of goods, labour division and the rise of multinational enter- 
prises. This was in turn superseded by the third industrial revolution during the 1970s, which employed electronics and information technology to achieve increased automation of manufacturing processes. Machines took over not only a substantial proportion of manual labour but also some parts of non-manuals' work (Kagermann, H. et al. 2010) (Figure 1).

Based on the findings of an empirical survey in six industrialized countries, the study analyses both the opportunities and challenges of Industrie 4.0 for the economy. First, the question arises as to what is new about the concept of Industrie 4.0? The introduction of the Internet of Things and Services (IoT) into the manufacturing world, which is referred to as Industrie 4.0, is about to introduce a completely new approach to production. Embedded manufacturing systems within factories are vertically networked with business processes and horizontally connected to value networks that can be managed in real time: from the moment of a customer's order right through to outbound logistics.
Together with industrial partners, researchers mainly from the economic sciences and engineering sciences are developing prototypes of such future smart factories (Schun, G. et al. 2017; Tolio, T. et al. 2019). Smart factories allow individual customer requirements to be met and mean that even individual items can be manufactured profitably. Dynamic business and engineering processes enable last-minute changes to production and deliver the ability to respond flexible to disruptions and failures on behalf of suppliers. Transparency is provided over the manufacturing process, facilitating optimized decision-making.

\section{Industrie 4.0 - what are their achievements to this day?}

The first three industrial revolutions came about as a result of mechanization, electricity and IT. Now, the introduction of the combination of the internet and services in the manu-

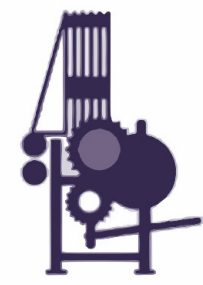

First mechanical loom 1784

1. industrial revolution follows introduction of water- and steam-powered mechanical manufacturing facilities

End of 18 th century

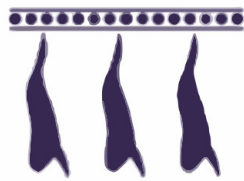

First production line,

Cincinnati slaughterhouses 1870

2. industrial revolution follows introduction of electrically-powered mass production based on the division of labour

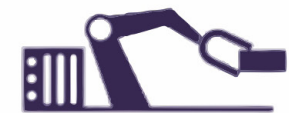

First programmable logic controller (PLC), Modicon 084 1969

3. industrial revolution uses electronics and IT to achieve further automation of manufacturing

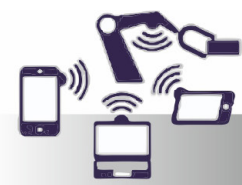

4. industrial revolution based on Cyber-Physical Systems

Fig. 1. Industrial revolutions during the history. Source: Forschungsunion and acatech, 2013. 
facturing environment is ushering in a fourth industrial revolution. In the future, businesses will establish global networks that incorporate their machinery, warehousing systems and production facilities in the shape of $\mathrm{Cy}$ ber-Physical Systems (CPS). Europe with its strong industrial core is thus uniquely positioned to tap into the potential of a new type of industrialization: Industrie 4.0.

A revolution always battles with the "old" world (Winter, J. 2010). Industrie 4.0 is extending the analogue and physical world to a digital environment. In this context, revolution means that system boundaries are expanded - not only physically but also virtually. From now on smart factories are built and connected to the smart supply chain. With the help of digital twins - e.g. of the product or even the production systems - the system can be mapped in a virtual world. These changes offer new opportunities to increase the productivity and emerge new business models (ScHuH, G. et al. 2017). That implies organizational and individual competences required by a digitized world being expanded. This is the reason why agile working methods should be adopted (Cooper, R.G. and FriIs Sommer, A. 2020).

\section{Industrie 4.0 - what does it take to go a step forward?}

Professionals from science and industry become more and more familiar with the concept of Industrie 4.0. Since 2015, the German initiative 'Plattform Industrie 4.0 ' brings together companies, trade unions, associations, science and politics to join forces. We see more and more Industrie 4.0 use cases, projects, demonstration centres and competence centres emerging all-around in Europe. But many people still underestimate just how radically and how rapidly we will need to change. Recent studies suggest that Industrie 4.0 may have the same dramatic effects on the geography of knowledge and innovation in Europe as the previous three industrial revolutions (KAGERMANN, H. and Winter., J. 2018; BAlland, P.A. et al. 2019), especially when developing new data-driven business models and disruptive innovation. When it comes to the broader public, more and more people are probably at least aware of the buzzword Industrie 4.0. The topic has finally made it to mainstream media. But still, most people will start to understand and to enjoy Industrie 4.0 not until they really experience its benefits first hand - for example, in terms of better / cheaper / more customized products and services. Or as workers in a smart factory: machines will take over more and more physically wearing and monotonous tasks; workers will be able to work more flexibly and with more individual choice and responsibility. Intelligent assistance systems will help employees to perform their tasks and support lifelong learning.

\section{The smart factory}

The ideal smart factory employs a completely new approach to production: machines and products, production equipment and employees are digitally connected with each other. The production system is highly digitized and makes it possible to track its status and productivity. Smart products are uniquely identifiable, may always be located and know their own history, current status and alternative routes to achieving their target state. The embedded manufacturing systems are vertically networked with business processes within factories and enterprises and horizontally connected to dispersed value networks that can be managed in real time - from the moment an order is placed right through to outbound logistics (XU, L.D. and DUAN, L. 2019). In the manufacturing environment, so called Cyber-Physical Systems comprise smart machines, storage systems and production facilities capable of autonomously exchanging information, triggering actions and controlling each other independently. This facilitates fundamental improvements to the industrial processes involved in manufacturing, engineering, material usage and supply chain and life cycle management (Figure 2). 


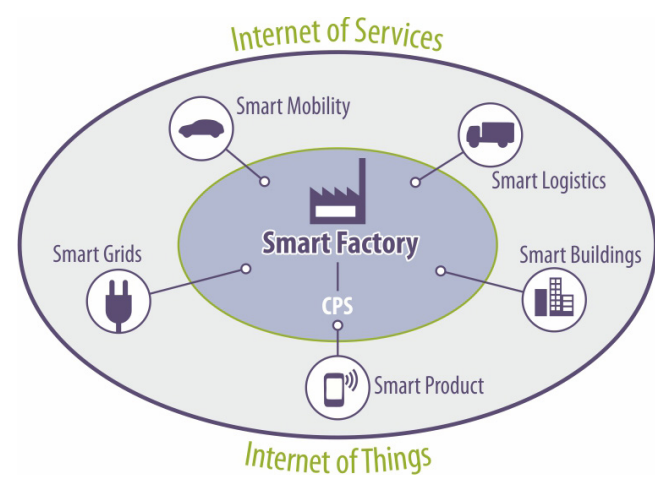

Fig. 2. Smart factories as part of the Internet of Things and Services. Source: Acatech, 2013. and Ciffolilli, A. (2020). A necessary precondition is the standardization and modularization of several single process steps and the programming of virtually adaptable models of such modules. Therefore, operating processes can be planned, coordinated and controlled. Moreover, the interconnection enables the continuous exchange of data that are necessary to adjust processes automatically and according to a specific situation. Here, the application of CPS allows a decentralization of the process control. It can be transferred to components that process ambient data by using embedded systems. In the next step, precise control commands can be derived. This increases the flexibility in production.

\section{Industrie 4.0 and the future of work}

According to recent studies (PARK, K.T. et al. 2020), in future roughly every object will have a digital twin with which enterprises can do many things in virtual space. By means of cyber-physical systems, the real and virtual world is further merging. For instance, much better simulations of products and production processes will be possible, meaning that less energy and resources must be expended in trial runs. The results of this study suggest that there is also an increasing connectedness within manufacturing and along value chains. This leads to a higher degree of automation, improved manufacturing quality, faster innovation cycles, and lower consumption of resources (KAGERMANN, H. and WinTER, J. 2017). Since all physical objects can be interconnected via the internet, we can, for example, make just-in-time logistics even better and prevent machine failures through predictive maintenance. Both prevent idle periods in production, thus saving resources.

Following the logic of the Internet of Things (IoT), assets, machines and components can exchange information continuously. Therefore, production- and logistic processes become integrated and, therefore, can be controlled and coordinated in real time and from spatial distance (Muscio, A.
The digital transformation will enable companies to react faster and more precisely to changing customer needs and new market conditions. It is already well understood that a fast implementation of data-based business models and a high level of flexibility, adaptability, and willingness to change among organizations and its employees are crucial for success in the face of global competition. As Bosснма, R. (2017) showed, a region has a higher probability to develop innovative goods when these are related to existing goods and value chains in a region. This means that there is a risk that regional disparities will be exacerbated by technological change - with effects on the regional labour market. This is the reason why key factors in the successful introduction of innovative processes and products include the acceptance of new technologies by employees and the design of attractive forms of work. At the same time, the higher degree of flexibility, in turn, opens the opportunity for workers to also achieve a higher level of work-life-balance and to safeguard their long-term employability by personalized reand up-skilling measures. In this context, the ability of workers to learn (and retrain) 
throughout the span of their careers is key to ensuring their future employability (lifelong learning) (McAfee, A. and Brynjolfsson, E. 2017). Companies share the responsibility by providing the corresponding education and training, and their employees obviously benefit from these measures.

Some company leaders are already dreaming of relocating value that was lost in the past two decades to East European and Asian countries (Fuchs, M. and Winter, J. 2008; Winter, J. 2008), where labour costs were significantly lower than back home. In the world of smart production however, a countries' competitive advantage is rather determined of sophisticated country infrastructures, innovation and know-how than from cost benefits of mass production. However, Industrie 4.0 may have the same dramatic effects on the geography of knowledge and innovation in Europe as the previous industrial revolutions (BALland, P.A. et al. 2019). Contrary to some fears about automated factories being orphan places (FREY, C. and Osborne, M. 2013), the fourth industrial revolution will provide new and often better job opportunities for skilled human workers.

In this perspective, a skilled labour force is crucial in order to introduce the entirely new production approach. The European and national ability to manage complex industrial processes in multi-stakeholder networks becomes a key factor for success. Another asset is the country's specialization in research, development and production of innovative manufacturing technologies. Universities, research institutes and companies are constantly developing innovative solutions for enhanced manufacturing. That is why STEM (Science, Technology, Engineering and Math) education becomes still more important. Hybrid skills become more and more important: future engineers need additional mechatronics and software skills. Managers need business skills as well as technical skills (e.g. data science). And: soft skills also play an important role in a connected economy/society (e.g., collaboration, conflict management, foreign language skills). As mentioned earlier, cyber physical systems consist of networks of small computers, equipped with sensors and actuators. Such embedded systems are integrated in materials, products, devices and machine parts and connected via the Internet. This constitutes the so-called Internet of Things (IoT), where the boundaries between the physical and digital world become more and more blurred. Moreover, there are tighter interactions between human users and their connected personal devices that lead to an Internet where human users become more central than ever. This means people are not seen only as end users of services and applications but become active elements of the so-called Internet of People (IoP).

\section{What Europe can do to join the fourth industrial revolution}

There is still disagreement in the literature about the extent to which Industry 4.0 can reduce regional disparities or, in certain circumstances, increase them. According to Muro, M. et al. (2019), there are differences across metropolitan regions in the US regarding their exposure to automation-driven task replacement. On the other hand, BARzotTo, M. and De Propris, L. (2019) argue that regions that have been left behind will find their way back if they specialize in smart processes, products and services that they can market globally. Muscio, A. and Ciffolilli, A. (2020) show that EU researches and SME funding play an important role in technology integration and increased competitiveness. For most of the experts we surveyed, Industrie 4.0 offers great potential for European regions. This is because the deployment of Industrie 4.0 solutions is seen as one means of promoting the reshoring of manufacturing capacity mainly from East Asia. According to our empirical findings, a higher degree of digitization and automation and the resulting productivity gains are keys to the regional competitiveness of industry in Europe.

Germany, for example, developed in 2013 a 'digital journey' and strategy to lead companies of each size to a high degree of dig- 
itization and to save their competitiveness. Networking platforms are founded to guarantee the exchange of the knowledge between companies, science, policymakers and trade unions. Enterprises share their best practices of Industrie 4.0 and help other companies on their evolutional way to the fourth industrial revolution. Politics support their development with public funding and focused research projects. Moreover, companies are offered different programs to gain knowledge regarding Industrie 4.0 and its implementation funded by the government, unions and trade associations. Thus, Industrie 4.0 is all about networking and exchanging knowledge and experiences with all parts of the economy.

Moreover, especially for European countries, it is important that digital technologies are adopted by businesses in order to grow labour productivity and to benefit from the potentials of online commerce. Europe would benefit from an Industry 4.0 scheme to develop specific digitization plans for the industry. It is important to think about investment in developing a strong Europe-wide ecosystem of digital innovation hubs. In several regions digital manufacturing platforms have already been developed to help digitize the manufacturing process. Europe could also benefit from creating the right conditions for private investments to improve the digital infrastructure. However, Europe must overcome shortages in IT-skills of the citizens. According to the Digital Economy and Society Index (DESI), about 20 per cent of the European population has never used internet. That also limits the possibilities offered by the digital economy and society.

As our expert survey shows, data become more and more important and independent economic goods, have a value and are base of innovative and profitable business models. Once they have left factory, smart products are still connected via the internet and exchange massive volumes of data during their use. These big data are refined into smart data, which can then be used to control, maintain or enhance and improve smart products and services. They generate the knowledge that forms the basis of new business models.
The consolidation and refinement via real-time analytics and artificial intelligence is usually done in data-rich digital platforms, which will soon be the predominant marketplace. Quite a few companies have already connected smart products to the Internet and have started collecting and evaluating data. Ideally those platforms should combine device management with easy connectivity, data storage systems and an app store open for customized data-driven services provided by an open digital ecosystem. The quality of the digital innovation ecosystem and how fast it can be established will be crucial for a successful implementation of new datadriven business models. In addition, several challenges must be answered regarding financing, reliability, data security, Intellectual Property Rights (IPR)-protection, and finally standardization (Figure 3).

When it comes to the concept of Industrie 4.0 , there is an area of tension between the ubiquitous access to production and personal data in order to create value on the one side and the protection of privacy on the other side. Wherever companies or organizations running Industrie 4.0 applications use data that is directly or indirectly tied to a specific person, they will be subject to the General Data Protection Regulation (GDPR). The GDPR aims at harmonizing the regulatory frame-

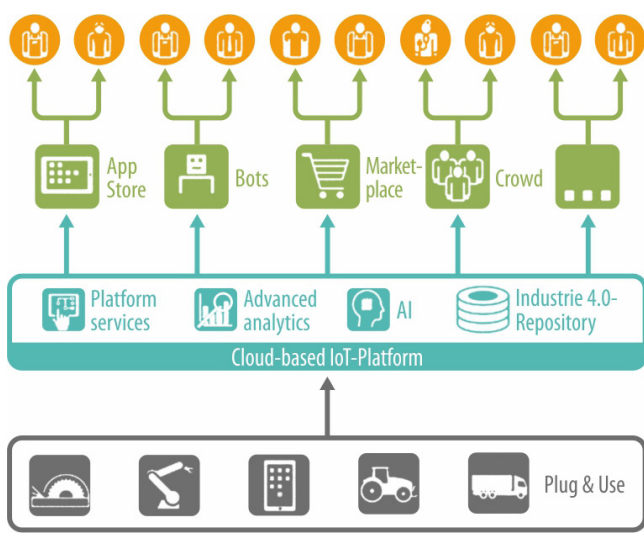

Fig. 3. Dimensions of Industrie 4.0. Source: Sснuн, G. et al. 2017. 
work regarding the usage of personal data in the European member states. The GDPR does not only affect European companies or organizations. It affects every business that handles or processes personal data of European citizens. According the GDPR, personal data must be processed in a lawful and transparent manner. This refers to specific purposes for collecting, storing and processing the data. Organizations must ensure that personal data is stored for no longer than necessary for the purposes for which it was collected. In addition, they are obliged to install appropriate technical and organizational safeguards that ensure the security of the personal data.

\section{Towards a data driven economy}

In the opinion of most of the experts we interviewed, we see a shift from productdriven to data-driven business models in all European core industries. Today, around 30 billion products around the world are connected to the Internet. Once they have left the factory, products are connected via the Internet. These products are data-driven, and they will be refined with digital services, so called smart services.

\section{How are smart services created?}

Smart services need data about the products, their use and consumers, and from other sources like traffic data or weather. These product-service-bundles must be able to extract valuable information from it via data analytics or machine learning. This is shown by the example of 'mobility as a service'. In order to implement this data-driven business model, a wide range of data is required: data of the locations of the users, cars or means of public transportation, movement data, weather data, information about restaurants at the destination etc. are required. And of course, mobile devices play a central role in gathering this information and data about how a certain service is used. In other words: it can be assumed that there is a shift towards data-driven innovations.

Smart services are created in dynamic digital ecosystems that evolve around digital platforms without geographical limitations. Why is that? According to our empirical findings, trustworthy partners are necessary to build up networks and to create innovative smart services. These partners often come from geographical proximity or at least existing business networks. Proximity is therefore a factor that should not be underestimated especially in the digital age, which seems to be borderless. It should be added that many companies don't have all the know-how to implement such data-driven smart services on their own. For example, companies need help from a start-up that is cutting edge in data analytics in order to get the information you require out of the vast amount of data. So, there must be a kind of digital business or innovation ecosystem. In my view, four different groups of the actors involved in the digital ecosystem can be distinguished (Table 1).

In the case of a smartphone, a tech giant such as Google or Samsung is the platform sponsor (design of the Android operating system) and acts as a platform provider (operation of the Android operating system and the app store). Application developers are those who make their apps available in the app store, the end users are the smartphone customers. Platform sponsor and platform operator can be the same company, but don't have to be.

Digital platforms consist of two parts:

- First: A "core" that is stable and changes only slowly - in our example the app store itself. This core defines technical and economic "rules of the game" such as interfaces and processes.

- Second: A "periphery" with a high development speed and heterogeneity. These are the app developers. They do not necessarily enter business relationships with each other but are often independent participants of the same platform. Due to virtual collaboration, spatial proximity 
Table 1. The structure of a digital innovation ecosystem*

\begin{tabular}{c|l}
\hline \multicolumn{1}{c|}{ Group } & \multicolumn{1}{c}{ Role } \\
\hline 01 End users & $\begin{array}{l}\text { The end users are the actual customers of the platform and use it for their own } \\
\text { purposes - be it the smart phone user or an industrial company that runs its } \\
\text { business with the help of such a platform. }\end{array}$ \\
\hline 02 Application developers & $\begin{array}{l}\text { The application developers create programs and services based on the tech- } \\
\text { nological platform. }\end{array}$ \\
\hline 03 Platform providers & $\begin{array}{l}\text { The platform providers deliver the technical infrastructure of the platform. In } \\
\text { the IT sector, this is a package of hardware and operating system based on } \\
\text { which programs and services can be developed. }\end{array}$ \\
\hline 04 Platform sponsors & $\begin{array}{l}\text { The platform sponsors are the actual "leaders" of the platform as such, as } \\
\text { they determine the design of the platform and own the intellectual property } \\
\text { of the platform. }\end{array}$ \\
\hline
\end{tabular}

*Edited by the author.

hardly plays a role in digital platform relationships (MOORE, J.F. 1993; KAGERMANN, H. and WinTER, J. 2017).

In platform logic, the consumer interacts with both the platform operator and the providers in the platform's periphery, the app developers. In order to be able to use the offers on a platform, the consumer enters a relationship with the platform. He logs in and user-related data is collected. On the platform, the consumer meets the providers: he buys, consumes and uses the offers on the platform. Over time, profile information is supplemented by information that arises from using the applications on the platform (Silvestri, S. and Gulati, R. 2015; Cusumano, M. et al. 2019) (Figure 4).

A

Traditional business model

=> one-sided market (linear)

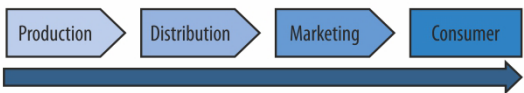

$\mathrm{B}$

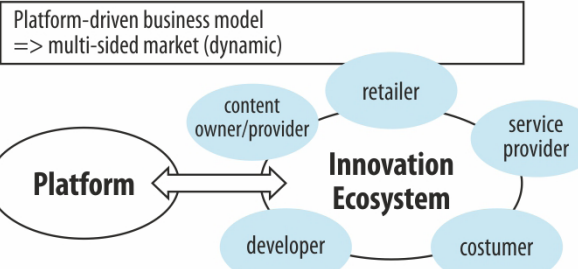

Fig. 4. From one-sided to multi-sided markets. Source: Tiwana, A. 2013, Winter, J. 2018.

\section{Digital platforms as a future field of economic geography research}

What are the special characteristics of platforms when it comes to competition in the digital era of manufacturing at a global and regional level? The empirically derived answer is that service platforms create new virtual control points instead of geographical or physical control mechanisms. Not only do they provide the rules, standards and processes according to which the different players in the digital ecosystems get connected and do business. They also serve as a central interface to the customers at a global level. Digital platforms are discussed in the economics literature under the concept of multi-sided markets (Evans, P. and GAWER, A. 2016). Case studies of geographical marketplaces are abundant in economic geography literature (NocKE, V. et al. 2007). The concept of virtual marketplaces and multi-sided platforms are not yet widely used in the economic geography research and should be taken more into account when assessing a globalized industry that is increasingly networked via software platforms. Multi-sided markets have special characteristics and can unfold certain dynamics that may in certain cases call for action from the regulatory authorities. All involved actors in the multisided market depend on each other and on the platform: creating APPs for the app store 
wouldn't be attractive if no one was using android as an operating system. That's why network effects emerge: the benefits of one side depend on the participation and desired transactions of the other side and vice versa.

Due to the network effects and economies of scale, competitors may face significant market entry barriers (RYSMAN, M. 2009). And since many digital platforms in the B2Csector initially focus on the fast growth of their user base rather than sales growth, the growth of the platform into a very powerful position in the market or a quasi-monopoly may take place without major takeovers. That's why regulatory instruments that rely on turnover thresholds may be too slow in these cases. So, what are the benefits and risks for customers and consumers in digital platforms, and are there spatial effects?

\section{Risk of data monopolies}

If a digital platform takes on the role of a quasi-monopoly the opportunities for consumers as well as for other actors in the ecosystem to find substitutes for the dominant platform such as virtual or geographical marketplaces are often limited. This leads to so called lockin effects. Here, interoperability and portability obligations may be a means of restoring competition between different platforms and avoiding lock-in effects. However, such obligations, especially in early market phases, can make differentiation and competition between the platforms more difficult.

In the General Data Protection Regulation, the European Union (European Union, 2019) established a right to data portability. Its aim is to strengthen data protection, consumer protection and the competition for privacyfriendly technologies. Ultimately, it is intended to strengthen the control over the personal data. The EU had in mind cases in which, for example, a user of a social network, a music portal or certain mobile apps wants to change the provider. If the legal requirements are fulfilled, the persons concerned have the right to receive their personal data in a suit- able format (e.g., via a USB stick, a CD, the private cloud or a barcode), to transmit their personal data to another provider. But it is not yet sufficiently clarified what is meant by personal data "provided" by the data subject. It includes personal data that relate to activity of the consumer or result from the observation of an individual's behaviour. But there is also data resulting from subsequent analysis of that behaviour: data that has been created as part of the data processing, e.g., by a personalization of certain services, for example personalization of recommendation systems. According to the Article 29 working group, which serves as an advisory body on the GDPR, these kinds processed data are not covered by the right to data portability.

Lock-in effects vs. increased number of options and comparability

Platforms can reduce information asymmetries - for example when consumers exchange ratings and assessments of services and products. Consumers can easily obtain information about services and products. The offers and products of a platform can also change and adapt over time. Thus, auction platforms become professional marketplaces at the expense of stationary retailers and regional shops. Once the users have agreed to the terms of the virtual platform, they are practically committed to it and must live with the changing conditions - for better or for worse.

In individual cases it may be the case that the provider of the platform also appears as an application provider (TiwanA, A. 2013). Examples of this are Amazon when it competes with its own listings with its sellers, and Google when its own listings are preferred in the search results. From the consumer's point of view, caution is called for here. If platforms compete with their suppliers on the geographical periphery, then they could possibly present their own products more prominently. Consumers may be restricted in their choice. In addition, platform providers have more than suppliers the chance to take 
over markets and to displace virtual as well as stationary competitors - regarding certain applications (Feldman, M.P. et al. 2019). They thus also strengthen their own competitive position in relation to other platforms. This has a lasting effect on the consumer, as its influence on the market is limited. What we also know from the interviews: from a geographical point of view, moreover, stationary suppliers are much more limited in their market opportunities than monopoly-like platform companies.

\section{'Privacy bargain' vs. data sovereign}

Many platforms are kind of "steering" their users through optical presentations and presettings. This has implications for consumer protection and it also has effects on relations with geographically located as well as platform-based competitors of the platform. Consumers may be restricted in their choice. In addition, under the keyword 'Privacy bargain' it says that if the user does not pay for the use, he can assume that he is the product himself. The operators of the platform are accused of always leaving the users in the dark about the value of the data that the users bring in. The use of data for advertising purposes suffers from an information and transparency gap between provider and user. The user who consents to the use of data for these purposes is blind because he does not know the true value of his data. In return, however, experiments show that users are all too willing to contribute their data in order not to have to make the slightest financial contribution to a service (privacy paradox) (BARTH, S. and De Jong, M.D.T. 2017). When it comes to privacy, there is also a need for supporting and to give incentives for technical solutions.

The principles 'Privacy by design' and 'Privacy by default' are also part of the GDPR (European Union, 2019). Already in the development stage of a system, data protection is to be technically integrated (Privacy by design). In addition, the factory settings should be designed to be data protection friendly
(Privacy by default). Users who are not that into technology and therefore not able to adapt data protection settings are protected by this principle. Data-mining algorithms could take privacy and data sovereignty into account as an intrinsic property (privacy-preserving data analytics). This is also in the interest of regional market players who could be subject to discrimination due to the market power of the platform monopolists. However, there is a lack of relevant economic geography research.

Dynamic and individual pricing vs. transparency of algorithm-based decision processes

Regarding consumer and stationary seller protection, algorithm-based decision processes are a topic that is widely discussed (Metawa, N. et al. 2017). One field of application of algorithm-based decision processes is pricing. Today, repricing algorithms are among the most important success factors in international e-commerce. In repricing, an algorithm uses publicly available data sources (including price search engines) in order to enable retailers to quickly adjust their own prices to the current competitive and demand situation at any time. Unlike repricing, individual pricing focuses on the consumer. Individual pricing is particularly common in the US. For example, some US companies made pricing dependent on the device used. The reasoning behind this refers to the higher prices of Apple devices, for example. It is assumed that Apple users have a higher budget than the average consumer and would therefore accept higher prices. With individual pricing, however, prices can also be set into marital status, age and gender, time, place of residence and numerous other variables. From a consumer protection point of view, this form of pricing raises questions. It already finds its limits in Germany through data protection. Regarding algorithm-based decision process, there's a discussion about establishing transparency and accountability. 
New industrial opportunities with artificial intelligence

What was repeatedly heard in the expert interviews is that data is becoming an economic good, which is what inspires some to speak of the data economy or data capitalism (Brynjolfsson, E. and KAHIN, B. 2002). The required data are merged, analysed, and interpreted on digital, usually cloud-based technology platforms, with the help of artificial intelligence and machine-learning methods and tools. Autonomous software systems such as self-learning robot advisers or assistance systems contribute to a personalized and convenient user experience (Acatech, 2017). Reconfiguration is no longer a manual process but autonomous and dynamic. This provides us with highly adaptable processes on all organizational levels for the first time: from the factory floor to the business level, which is often referred to as a new wave of business process reengineering. As a result, the collection and use of data will become omnipresent. Self-learning and autonomous systems driven by artificial intelligence use that to make independent decisions, also building on their own learning processes. These developments represent a challenge, but above all an opportunity for Europe. The guiding principle of action here should be that digitalization is primarily shaped by people for people.

Current research and progress in the field of artificial intelligence are mainly based on advances in machine learning, which in turn are made possible by the development of powerful algorithms, more powerful hardware, increasing computing power and the cost-effective availability of mass data (WAHLSTER, W. 2014). Learning ability was already defined at the beginning of artificial intelligence (AI) research as the basic cognitive ability of "intelligent" technical systems. Machine learning aims to ensure that machines automatically deliver meaningful results without explicit programming of a specific solution path. Special algorithms learn models from the existing example data, which can then also be applied to new, previously unseen data. Three learning styles are distinguished: monitored learning, unsupervised learning and intensified learning. Machine learning with large neural networks is called deep learning. Machine learning methods are used for data mining, generating smart data and in practically all modern AI systems. All these new technologies and analytical methods can provide new opportunities for the whole economy, particularly for manufacturing industry, and this also means a new challenge for economic geographical research.

\section{Conclusions and outlook}

As stated before, the concept of Industrie 4.0 is - with few exceptions - underrepresented in economic geography research. Consequently, it was the purpose of this paper to intensify the Industrie 4.0 debate in economic geography by showing the evolutionary and disruptive potential of Industrie 4.0 on Europe's industrial landscape.

As the empirical results of the qualitative study show, Europe's small and mediumsized enterprises play a crucial role in the innovation process of the manufacturing industry. These often family owned companies distinguish themselves from other companies through an extraordinary level of specialization, know-how and innovative capacities. Often, they are world leaders in their niche markets - and literally hiding in many of the small towns and villages throughout Europe. Although mainly unknown in public, besides multinational corporations and state-owned companies, small and mediumsized enterprises form an essential backbone of the European economy and are actively contributing to the industrial transformation process. Europe's strong automotive, machinery and plant manufacturing companies and their know-how in embedded systems as well as automation engineering are reasons for the continent's pole position in the international race towards the fourth industrial revolution. These so-called hidden 
champions have also been successfully introducing information and communication technologies for several decades.

The trend towards Industrie 4.0 is inspiring enterprises to set up their core processes more efficiently and develop products and services digitally. This transformation will take a rather evolutionary path. At the same time, digital business models, two-sided platform markets, and data-driven innovation ecosystems have a disruptive potential. That is because contemporary business models can be cannibalized by new market participants and well-funded start-ups in a short time. In addition, disruptive innovations can hurt successful, well-managed companies as well as previously competitive regions. The boundaries between manufacturing industries, service enterprises, IT-providers and tech giants are becoming blurred. Corporates as well as small and medium-sized enterprises need additional competencies and skills, for example in the areas of data science, data analytics, machine learning and agile working methods.

However, intense software know-how and the awareness of new data-driven business models might still prove to become the Achilles' heel of many of the countries' hidden champions. Uncertain about how Industrie 4.0 will change (evolutionary, but radical) their current business models, mechanical firms keep a careful watch over the Silicon Valley, where venture capital driven high-tech-start-ups are currently also discovering the lucrative new markets that are about to come into being. Another crucial aspect is the development of international standards and norms. Without compatible standards, a comprehensive integration of machines, products and services will be difficult to achieve as the study results show.

Even though European companies build open digital platforms and develop datadriven business models, the implementation remains a major challenge for many countries and regions in a heterogeneous European industrial landscape. Nevertheless, nothing is lost yet. The global race in the industrial sector is still open as to which communication and cloud infrastructures will set the standards, what the dominant Business-toBusiness platforms will be in the future and which companies will be most successful in turning data into concrete added value. It is therefore the right moment to take a step forward and shape the digital transformation of the industry to our common benefit. The goal of the European Union to create a single digital market to allow digital opportunities for people and businesses and enhance Europe's position as an industrial world leader is honourable. The final implementation of the single digital market is still pending. However, this implementation is the next step in achieving the competition-relevant economies of scale and making Europe's regions fit for the global Industrie 4.0 race.

\section{REFERENCES}

Acatech - National Academy of Science and Engineering 2013. Recommendations for implementing the strategic initiative INDUSTRIE 4.0. Securing the future of German manufacturing industry. Final report of the Industrie 4.0 Working Group. Available at https://www.acatech.de/wp-content/uploads/2018/03/ industrie_4_0_umsetzungsempfehlungen.pdf

Acatech - National Academy of Science and Engineering / Fachforum Autonome Systeme 2017. Autonomous Systems - Opportunities and risks for business, science and society. High-Tech-Forum of the German Government. Munich, Gotteswinter \& Aumaier, 26-44.

Bailey, D. and De Propris, L. 2019. Industry 4.0 Regional disparities and transformative industrial policy. Regional Studies Policy Impact Books 1. (2): 67-78

Balland, P.A., Boschma, R., Crespo, J. and Rigby, D.L. 2019. Smart specialization policy in the European Union: relatedness, knowledge complexity and regional diversification. Regional Studies 53. (9): 1252-1268.

BARTH, S. and De Jong, M.D.T. 2017. The privacy paradox - Investigating discrepancies between expressed privacy concerns and actual online behaviour - A systematic literature review. Telematics and Informatics 34. (7): 1038-1058.

Barzotto, M. and De Propris, L. 2019. Skill up: smart work, occupational mix and regional productivity. Journal of Economic Geography 19. (5): 1049-1075.

Boschмa, R. 2017. Relatedness as driver behind regional diversification: a research agenda. Regional Studies 51. (3): 351-364. 
Brynjolfsson, E. and KaHIN, B. 2002. Understanding the Digital Economy: Data, Tools and Research. Cambridge, MA, MIT Press.

Ciffolilli, A. and Muscio, A. 2018. Industry 4.0: national and regional comparative advantages in key enabling technologies. European Planning Studies 26. (12): 2323-2343.

Cooper, R.G. and Friss Sommer, A. 2020. New-product portfolio management with Agile challenges and solutions for manufacturers using Agile development methods. Research Technology Management 63. (1): 29-38.

Cusumano, M., Gawer, A. and Yoffie, D.B. 2019. The Business of Platforms: Strategy in the Age of Digital Competition, Innovation, and Power. New York City, Harper Collins.

Daugherty, P. and Wilson, H.J. 2018. Human + Machine. Reimagining Work in the Age of AI. Cambridge, Ingram Publisher Services.

European Union 2019. General Data Protection Regulation (EU) 2016/679 (GDPR). Available at https://ec.europa.eu/info/law/law-topic/dataprotection_en (accessed 12.03.2020)

Evans, P. and Gawer, A. 2016. The Rise of the Platform Enterprise. New York, The Center for Global Enterprise.

Feldman, M.P., Guy, F. and Iammarino, S. 2019. Regional Income Disparities, Monopoly \& Finance. Chapel Hill, NC, Kenan Institute of Private Enterprise Research, Paper No. 19-32.

Forschungsunion and acatech 2013. Recommendations for implementing the strategic initiative INDUSTRIE 4.0. Securing the future of German manufacturing industry. Final report of the Industrie 4.0 Working Group. Frankfurt, Germany, Forschungunion.

Frey, C. and Osborne, M. 2013. The Future of Employment. How susceptible are jobs to computerisation? Oxford, Oxford University Press.

Fuchs, M. and Winter, J. 2008. Competencies in subsidiaries of multinational companies. The case of the automotive supply industry in Poland. The German Journal of Economic Geography 52. (1): 209-220.

Fuchs, M. 2020. Does the digitalization of manufacturing boost a 'smart' era of capital accumulation? The German Journal of Economic Geography 64. (3): 1-11.

Glaeser, J. and LaUdeL, G. 2004. Experteninterviews und qualitative Inhaltsanalyse. Wiesbaden, VS Publishers.

Göтz, M. and Јалкошsка, В. 2017. Clusters and Industry 4.0 - do they fit together? European Planning Studies 25. (9): 1633-1653.

HAIDER, M. 2020. Electrifying times: restructuring and decision-making in an automobile concern in the $21^{\text {st }}$ century - The case of BMW Group. Hungarian Geographical Bulletin 69. (2): 119-135.

Kagermann, H., Österle, H. and Jordan, J. 2010. IT-Driven Business Models. New Jersey, Hoboken.

Kagermann, H. and Winter, J. 2017. Industrie 4.0 und plattformbasierte Geschäftsmodellinnovationen
(Industrie 4.0 and platform-based business model innovation). In Praxishandbuch Industrie 4.0. Ed.: Lucks, K., Stuttgart, Schaeffer Poeschel, 21-32.

Kagermann, H. and Winter, J. 2018. The second wave of digitalization. In Germany and the World 2030: What will change. How we must act. Eds.: MAYR, S., Messner, D. and Meyer, L., Berlin, Econ, 216-227. McAfee, A. and Brynjolfsson, E. 2017. Machine, Platform, Crowd. New York, Norton \& Company.

Metawa, N., Kabir Hassan, M. and Elhoseny, M. 2017. Genetic algorithm-based-model for optimizing bank lending decisions. Expert Systems with Applications 80.75-82.

Molnár, E., Kozma, G., Mészáros, M. and Kiss, É. 2020. Upgrading and the geography of the Hungarian automotive industry in the context of the fourth industrial revolution. Hungarian Geographical Bulletin 69. (2): 137-155.

MoORE, J.F.1993. Predators and prey: a new ecology of competition. Harvard Business Review 71. (3): 75-86.

Muro, M., Maxim, R. and Whiton, J. 2019. Automation and Artificial Intelligence: How machines are affecting people and places. Available at https://www.brookings.edu/research/automation-and-artificial-intelligence-how-machines-affect-people-and-places/ (accessed 12.03.2020)

Muscio, A. and Ciffolilli, A. 2020. What drives the capacity to integrate Industry 4.0 technologies? Evidence from European R\&D projects. Economics of Innovation and New Technology 29. (2): 169-183.

Nocke, V., Peitz, M. and Stahl, K. 2007. Platform ownership. Journal of the European Economic Association 5. (6): 1130-1160.

PARK, K.T., LeE, J. and KIM, H. 2020. Digital twinbased cyber physical production system architectural framework for personalized production. International Journal of Advanced Manufacturing Technology 106. 1787-1810.

Rysman, M. 2009. The economics of two-sided markets. Journal of Economic Perspectives 23. (3): 125-143.

Schuh, G., Anderl, R., Gausemeier, J., ten Hompel, M. and WAHLSTER, W. (eds.) 2017. Industrie 4.0 Maturity Index. Managing the Digital Transformation of Companies. Acatech Study. Munich, Utz Publishers.

Silvestri, L. and Gulati, R. 2015. From periphery to core: A process model for embracing sustainability. In Leading Sustainable Change: An Organizational Perspective. Eds.: Henderson, R., Galati, R. and Tushman, M., Oxford, Oxford University Press, $81-111$.

Szalavetz, A. 2017. Industry 4.0 in factory economies. In Condemned to be Left Behind? Can Central and Eastern Europe Emerge from its Low-Wage Model? Eds.: Galgóczi, B. and DrahokoupiL, J., Brussels, European Trade Union Institute (ETUI), 133-152.

Trwana, A. 2013. Platform Ecosystems: Aligning Architecture, Governance, and Strategy. Waltham/Massachusetts, Morgan Kaufmann. 
Tolio, T., Copani, G. and Terkaj, W. 2019. Factories of the Future. The Italian Flagship Initiative. Heidelberg, Springer.

WAHLSTER, W. 2014. Semantic technologies for mass customization. In Towards the Internet of Services. Eds.: Wahlster, W., Grallerrt, H.-J., Wess, S., Friedrich, H. and WidenKa, TH., Heidelberg, Springer, 3-14.

Winter, J. 2008. Spatial division of competencies and local upgrading in the automotive industry: Conceptual considerations and empirical findings from Poland. In Globalising Worlds and New Economic Configurations. Eds.: TAYLOR, M. and TAmasy, C., Aldershot, U.K., Ashgate, 113-124.
WINTER, J. 2010. Upgrading of TNC subsidiaries: The case of the Polish automotive industry. International Journal of Automotive Technology 10. (2-3): 145-160.

WinTER, J. 2018. Europe and the platform economy / Europa und die Plattformoekonomie. In Service Business 4.0 / Dienstleistungen 4.0. Eds.: BRUHN, M.

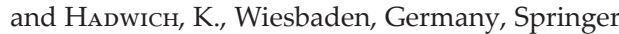
Gabler, 71-88.

XU, L.D. and DuAn, L. 2019. Big data for cyber physical systems in industry 4.0: a survey. Enterprise Information Systems 13. (2): 148-169. 
